\title{
RNAi-mediated silencing of the myo-inositol-1-phosphate synthase gene (GmMIPS1) in transgenic soybean inhibited seed development and reduced phytate content
}

Received: 21 October 2005 / Accepted: 15 November 2005 / Published online: 4 January 2006

(C) Springer-Verlag 2006

\begin{abstract}
Inositol plays a role in membrane trafficking and signaling in addition to regulating cellular metabolism and controlling growth. In plants, the myo-inositol1-phosphate is synthesized from glucose 6-phosphate in a reaction catalyzed by the enzyme myo-inositol-1phosphate synthase (EC 5.5.1.4). Inositol can be converted into phytic acid (phytate), the most abundant form of phosphate in seeds. The path to phytate has been suggested to proceed via the sequential phosphorylation of inositol phosphates, and/or in part via phosphatidylinositol phosphate. Soybean [Glycine max (L.) Merrill] lines were produced using interfering RNA (RNAi) construct in order to silence the myo-inositol-1phosphate (GmMIPS1) gene. We have observed an absence of seed development in lines in which the presence of GmMIPS1 transcripts was not detected. In addition, a drastic reduction of phytate $\left(\mathrm{InsP}_{6}\right)$ content was achieved in transgenic lines (up to $94.5 \%$ ). Our results demonstrated an important correlation between GmMIPS1 gene expression and seed development.
\end{abstract}

Keywords Glycin ' Inositol $\cdot$ myo-Inositol 1-phosphate synthase $\cdot$ Phytic acid $\cdot$ Phytin globoid

RNA-interference $\cdot$ Seed development

A. C. S. Nunes · G. R. Vianna · G. de Capdeville $\cdot$ E. L. Rech

F. J. L. Aragão ( $₫)$

Embrapa Recursos Genéticos e Biotecnologia, PqEB W5 Norte, 70770-900 Brasília, DF, Brazil

E-mail: aragao@cenargen.embrapa.br

Tel.: + 55-61-34484777

Fax: + 55-61-34484777

A. C. S. Nunes

Departamento de Nutrição Humana, Universidade de Brasília, Campus Universitário, 70910-900 Brasília, DF, Brazil

F. Cuneo $\cdot$ J. Amaya-Farfán

Faculdade de Engenharia de Alimentos, R. Monteiro Lobato, Universidade Estadual de Campinas, Campus Universitário, 13083-970 Campinas, SP, Brazil
Abbreviations EMS: Ethyl methanesulfonate $\cdot$ MIPS: myo-Inositol 1-phosphate synthase - RNAi: Interfering RNA - RT-PCR: Reverse transcription polymerase chain reaction

\section{Introduction}

In plants, the myo-inositol-1-phosphate is synthesized from glucose 6-phosphate in a reaction catalyzed by the enzyme myo-inositol-1-phosphate synthase (EC 5.5.1.4). Inositol can be converted into phytic acid (phytate), the most abundant form of phosphate in seeds, accounting for $50-90 \%$ of total seed phosphorus in several species (Loewus and Murthy 2000; Raboy 2001, 2002; Raboy et al. 2001). The path to phytate has been suggested to proceed via the sequential phosphorylation of inositol phosphates, and/or in part via phosphatidylinositol phosphate (Brearley and Hanke 1996a, b; Loewus and Murthy 2000; Raboy 2001, 2002; Hitz et al. 2002). Phytate is presumed to act as a phosphate storage compound (Brearley and Hanke 1996a, b). During germination, it is degraded by phytases, providing growing seedlings with phosphate, mineral cations and myoinositol (Loewus and Murthy 2000). Phytate forms complexes with mineral cations (mostly $\mathrm{K}^{+}, \mathrm{Mg}^{+2}$, $\mathrm{Ca}^{+2}$ and $\mathrm{Zn}^{+2}$ ), acting as mineral storage, a function made possible by the high density of negatively charged phosphate groups located around the myo-inositol ring.

myo-Inositol 1-phosphate synthase (MIPS) coding sequence has been characterized and cloned from a number of plant species, such as S. polyrhiza (Smart and Fleming 1993), Arabidopsis thaliana (Johnson 1994), Citrus paradisii (Abu-Abied and Holland 1994), common ice (Ishitani et al. 1996) and tobacco (Hara et al. 2000). Four highly similar GmMIPS ESTs have been identified in soybean: GmMIPS1, isolated from immature cotyledon, GmMIPS2 from root, shoot, flower and seed coat, GmMIPS3 from flower, leaves, buds and germinated cotyledons and GmMIPS4 from buds and young pods libraries (Hegeman et al. 2001). 
In spite of the numerous physiological investigations of phytate accumulation and storage, it is still not fully understood how plants synthesize phytate and how the phytate metabolism is coordinated with signaling mechanisms involving other inositol phosphates (Hitz et al. 2002). In addition, the phytic acid biosynthesis pathway in developing seeds is poorly understood (Shi et al. 2005). However, it is known that inositol phospholipids play a role in membrane trafficking and signaling, regulating cellular metabolism and controlling growth (for a review see Stevenson et al. 2000). Additionally, myo-inositol polyphosphates participate in chromatin remodeling, gene expression and mRNA export (York et al. 1999; Odom et al. 2000; Shen et al. 2003).

Raboy and Dickinson (1987) utilized phosphate starvation during seed development to produce soybean seeds with great reduction in the phytate content, demonstrating that phytate is not a requirement for seed viability or germination. Moreover, mutant lines of maize (Zea mays; Raboy et al. 2000), barley (Hordeum vulgare; Larson et al. 1998), rice (Oryza sativa; Larson et al. 2000), and soybean (Wilcox et al. 2000), presenting accentuated reduction of phytate levels, have not shown any effect on seed development. Mutant maize with a phenotype of reduced phytic acid, increased myo-inositol and reduced amounts of myo-inositol phosphate intermediates in the seeds showed a minimal effect on plant growth and development (Shi et al. 2005). These facts suggest that a high level of stored phytate is not a requirement for seed germination or seedling growth. In barley, phytase activity was observed during both seed maturation and development (Hatzack et al. 2001). Raboy and Dickinson (1987) showed that phytic acid levels increased steadily until late soybean seed maturation and reported accumulation of phytate throughout seed maturation. In contrast, Hegeman et al. (2001) found detectable levels of MIPS protein mainly during seed development, indicating high-level expression only in early cotyledonary stages. This fact may suggest that the conversion of glucose 6-phosphate to myo-inositol-1phosphate occurs earlier in seed development.

The potential of constructs encoding self-complementary hairpin RNA (hpRNA) to efficiently silence genes in plants has been previously demonstrated (Wesley et al. 2001). The self-complementary RNA transcripts form a double-stranded RNA (dsRNA) that triggers a sequence-specific mRNA degradation, in a process known as RNA-interference (RNAi). dsRNA is processed by an RNase III, called Dicer, into small interfering RNA (siRNAs). The strand of siRNA complementary to the target RNA becomes incorporated into a multi-protein complex (RISC) leading to mRNA degradation and gene silencing (Scherer and Rossi 2003).

In this report, we used the RNAi technology in order to silence the GmMIPS1 gene expression in soybean seeds. We demonstrate that the lack of expression of this gene in immature soybean seeds leads to an absence of accumulation of phytate globoids and is involved in seed development.

\section{Materials and methods}

\section{Cloning the GmMIPS1 fragment}

Total RNA was extracted using the RNAeasy kit (Qiagen) from $200 \mathrm{mg}$ of fresh tissue (2- to 4-mm seeds; stages D to F, according to Meinke et al. 1981). The remaining genomic DNA was eliminated by DNase digestion of the RNA samples. Two micrograms of total RNA from $2 \mathrm{~mm}$ immature soybean seeds were used to produce total cDNA using the Superscript II kit (Invitrogen). Primer pairs MIPSXba (5-CTCTAGAACCA CCGAACTTGTTCAC-3) and MIPSBamH [5-CGGA TCCAAATCTCAGCCTCATTTC-3, including the sites for $X b a \mathrm{I}$ and BamHI (underlined), respectively] and MIPSKpn (5-CGGTACCAAATCTCAGCCTCATT TC-3) and MIPSEco [5-GGAATTCACCACCGAA CTTGTTCAC-3, including the sites for $K p n I$ and Eco RI (underlined), respectively] were used to amplify two $706 \mathrm{bp}$ fragments from the GmMIPS1 gene (both fragments from coding sequence position 79-784, GenBank accession AF293970). RT-PCR reactions were carried out in a thermocycler (PTC-100, MJ Researcher, USA) in $50 \mu \mathrm{l}$ solution containing $40 \mathrm{ng}$ of cDNA, $60 \mathrm{mM}$ Tris-SO $\mathrm{SO}_{4}(\mathrm{pH} 8.9), 18 \mathrm{mM}\left(\mathrm{NH}_{4}\right)_{2} \mathrm{SO}_{4}, 2 \mathrm{mM} \mathrm{MgSO}_{4}$, $250 \mathrm{nM}$ of each dNTP; $200 \mathrm{nM}$ of each primer, $5 \mathrm{U}$ of Platinum Taq DNA Polymerase High Fidelity (Invitrogen). The mixture was treated at $95^{\circ} \mathrm{C}(5 \mathrm{~min})$ and subjected to 35 cycles of amplification $\left(95^{\circ} \mathrm{C}\right.$ for $1 \mathrm{~min}$, $50^{\circ} \mathrm{C}$ for $1 \mathrm{~min}, 72^{\circ} \mathrm{C}$ for $1 \mathrm{~min}$ ) with a final elongation cycle of $5 \mathrm{~min}$ at $72^{\circ} \mathrm{C}$. The $706 \mathrm{bp}$ fragments were cloned into the pGEMT-Easy vector for PCR products (Promega) and sequenced by using universal M13 and T7 primers on automatic sequencer (ABI Prism1 3700).

\section{RNAi construct and soybean transformation}

The GmMIPS1 fragments were excised from pGEMTEasy with $X b a \mathrm{I} / B a m \mathrm{HI}$ and $K p n \mathrm{I} / E c o$ RI, respectively, and inserted into the vector pKannibal (Wesley et al. 2001) to generate the plasmid pKanMIPS. The interfering cassette was removed with $N o t \mathrm{I}$ from the vector pKanMIPS and cloned into the site for NotI in the vector pAC321, which contains the gene ahas (that confers tolerance to the herbicide imazapyr) from $A$. thaliana (Aragão et al. 2000), generating the vector pMIPSGM. The cassette containing the GmMIPS1 hairpin will be mentioned hereafter as $\triangle G m M I P S$. The plasmid vector pMIPSGM was used to transform soybean (cv. Conquista) according to Aragão et al. (2000).

\section{Screening of transgenic plants by PCR analysis}

DNA was isolated from seeds or leaf disks according to Edwards et al. (1991). PCR reactions were carried out as described above, except that $\mathrm{MgSO}_{4}$ was replaced by 
$\mathrm{MgCl}_{2}$, and the Platinum Taq DNA Polymerase High Fidelity was replaced by Taq polymerase (Invitrogen). The primers MIPSKpn and MIPSEco were utilized to amplify a $706 \mathrm{bp}$ fragment from the $\triangle G m M I P S$ sequence. Primers 5-ACTAGAGATTCCAGCGTCAC-3́ and 5-GTGGCTATACAGATACCTGG-3́ were utilized to amplify a 685 bp sequence from the ahas gene.

\section{RT-PCR expression analysis}

Developing (4-5.5 mm long) and aborted (1.5-2.5 mm long) seeds were removed from immature pods and used for total RNA extraction as described above. Total RNA was used to produce cDNA using the reverse transcriptase Superscript II (Invitrogen), according to the protocol suggested by the manufacturer except that random decamers (Ambion Inc., Ustin, TX, USA) were utilized. PCR reactions were carried out as described above except that $25 \mathrm{ng}$ of cDNA (quantified using the DyNA Quant 200 fluorimeter, Amersham Pharmacia Biotech) was used as a template with 24 cycles of amplification. Primers MIPSKpn and MIPSEco were utilized to amplify a $706 \mathrm{bp}$ fragment from the GmMIPS sequences. The $706 \mathrm{bp}$ fragments of the MIPS-encoding sequence amplified from expressing seeds were cloned into the pGEMT-easy and sequenced. As an internal control, primers EF1F (5-TGTTGCTGTTAAGGATTTGAAGCG-3́) and EF1R (5-AACAGTTTGACGCATGTCCCTAAC-3) were utilized to amplify $358 \mathrm{bp}$ within the soybean housekeeping gene, tefS1 (elongation factor EF-1 $\alpha$; GenBank accession No. X56856).

\section{Southern blot analysis}

Genomic DNA was isolated using the DNeasy Plant Mini Kit (Qiagen). Southern blotting was carried as described (Sambrook and Russell 2001). Genomic DNA $(15 \mu \mathrm{g})$ was digested with $\mathrm{XhoI}$, separated on a $1 \%$ agarose gel and transferred to a nylon membrane (Hybond $\mathrm{N}+$, Amershan Pharmacia Biotech). Hybridization was carried out using the intron from $p d k$ gene (Wesley et al. 2001), present in the vector pMIPSGM, labeled with $\alpha^{32} \mathrm{P}$ dCTP, $\left.1.13 \times 10^{14} \mathrm{~Bq} \mathrm{~mol}^{-1}\right)$ using a random primer DNA labeling kit (Amersham Pharmacia Biotech) according to the manufacturer's instructions.

\section{Electron microscopy}

The transmission electron microscopy was carried out as described by Ma et al. (2004), and adapted as follows. Soybean seeds of the treatments described above were collected and immersed in $2.5 \%$ glutaraldehyde in $0.1 \mathrm{M}$ sodium cacodylate buffer at $\mathrm{pH} 6.8$ for 1 week at room temperature. The seeds were then transferred to fresh preparations of the same fixative and held for $30 \mathrm{~min}$ at $25^{\circ} \mathrm{C}$ and then for an additional $90 \mathrm{~min}$ at $4^{\circ} \mathrm{C}$. Samples were rinsed with the same buffer and post-fixed for $2 \mathrm{~h}$ at room temperature in $2 \%(\mathrm{v} / \mathrm{v})$ osmium tetroxide in $0.1 \%$ sodium cacodylate, $\mathrm{pH} 6.8$. The samples were washed in the same buffer, dehydrated in a graded ethanol series, and then embedded in Spurr's epoxy resin (Electron Microscopy Sciences, Ft. Washington, PA, USA). Ultra-thin sections were cut with a Diatome diamond knife (Diatome Ltd., Biel, Switzerland) using an ultramicrotome (Leica Microsystems, Heidelberger Strasse, Germany), collected on formvar-coated copper grids $(300 \times 75$ mesh) and stained with uranyl acetate and lead citrate. The sections were examined with a Zeiss EM 912 transmission electron microscope at $80 \mathrm{kV}$.

\section{Phytic acid determination}

Phytic acid was determined by HPLC using a modification of the procedure described by Sandberg and Ahderinne (1986). Samples of $0.5-0.7 \mathrm{~g}$ of intact soybean grains were pulverized manually in a mortar, and then extracted under vigorous mechanical agitation with $20 \mathrm{ml} 0.5 \mathrm{M} \mathrm{HCl}$ for $2 \mathrm{~h}$ at $20^{\circ} \mathrm{C}$. The extract was centrifuged $(17,300 \mathrm{~g}$ for $30 \mathrm{~min})$ and the supernatant removed, frozen overnight, centrifuged again and filtered through a $0.45 \mu \mathrm{m}$ membrane. The extract was evaporated to dryness under reduced pressure in a water bath with the temperature not exceeding $40^{\circ} \mathrm{C}$, with an acid trap that consisted of $\mathrm{NaOH}$ pellets in an Erlenmeyer flask. The residue was dissolved in $20 \mathrm{ml} 25 \mathrm{mM} \mathrm{HCl}$. The compound was separated and concentrated by ionexchange procedure using glass columns containing $0.5 \mathrm{~g}$ of dry resin (AG 1×4, 100-200 mesh, Bio-Rad). The residue was passed through the column, and the inorganic phosphate was removed from the resin with 10 and $5 \mathrm{ml}$ of $25 \mathrm{mM} \mathrm{HCl}$. The inositol phosphates were recovered with $10 \mathrm{ml}$ of $2 \mathrm{M} \mathrm{HCl}$. The eluant was evaporated to dryness and diluted with $0.5 \mathrm{ml}$ of ultrapure water and stored frozen until HPLC analysis. The mobile phase consisted of $0.05 \mathrm{M}$ formic acid:methanol (Merck, HPLC grade) 49:51 (v/v), and $1.5 \mathrm{ml}$ of tetrabutylammonium hydroxide (TBO-OH, 40\% in water; Fluka, Buchs, Switzerland) was added. The $\mathrm{pH}$ was adjusted to 4.3 by the addition of $5 \mathrm{M}$ sulfuric acid. The mobile phase was filtered through a Millipore filter (MF) $(0.45 \mu \mathrm{m})$ under vacuum and degassed by sonication for 15 min. A Varian model 9012 chromatograph was used. The reverse phase C-18 column (100 mm Hibar, Merck) was equilibrated with mobile phase for $3 \mathrm{~h}\left(28^{\circ} \mathrm{C}\right)$ and injections of $20 \mu \mathrm{l}$ of extracts and standard solutions

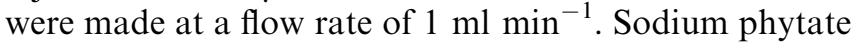
(Sigma) was utilized as external standard. Standard solutions were prepared in ultra-pure water using 4, 12 and $16 \mathrm{mg} \mathrm{ml}^{-1}$ of phytic acid with two injections in the HPLC column to construct the standard curve $(r=0.999)$. Retention times and areas were measures by a Star Chromatography Workstation and a Refractive 
Index detector (Varian Star 9040 RI). The phytic acid was identified by retention time of the standard compound.

Colorimetric assay for inorganic phosphorus determination

Available phosphorus values were determined by the method of Chen et al. (1956). Fifteen seeds from the second generation $\left(\mathrm{T}_{2}\right)$ of the subline $12 \mathrm{i} / 2$ were analyzed to compare the presence of inorganic phosphorus with non-transgenic seeds. Fifteen milligrams of tissue were removed from each soybean seed with a nail file, extracted with $200 \mu \mathrm{l}$ of $400 \mathrm{mM} \mathrm{HCl}$ solution at $4^{\circ} \mathrm{C}$ overnight. Samples were vigorously mixed, and $10 \mu \mathrm{l}$ were removed and diluted tenfold with Milli-Q water. Inorganic phosphorus values were determined using $100 \mu \mathrm{l}$ of freshly prepared Chen's reagent [water, $6 \mathrm{~N}$ $\mathrm{H}_{2} \mathrm{SO}_{4}, 2.5 \%(\mathrm{w} / \mathrm{v})$ ammonium molybdate, $10 \%(\mathrm{w} / \mathrm{v})$ ascorbic acid in the ratio 2:1:1:1]. The resulting blue color was read at $655 \mathrm{~nm}$.

\section{Results and discussion}

In order to produce soybean plants with silencing of the GmMIPSI gene, we generated an intron-spliced hpRNA vector (pMIPSGm) into which the GmMIPS1 gene fragment from soybean was directionally cloned to generate sense and anti-sense arms. The vector pMIPSGm was utilized to produce 16 soybean transgenic lines. Although myo-inositol phosphates are precursors of several metabolic pathways important for membrane biogenesis, signal transduction, stress responses, auxin physiology and cell wall biosynthesis, the primary transformants presented normal phenology (plant height, site of insertion of first pod, number of branches, internode length, foliar area, total number of flowers and pods) and were cultivated to set seeds in the greenhouse. Similar results were observed in previously published works in which low-level phytate mutants presented normal plant growth and seed development (Larson et al. 1998, 2000; Raboy et al. 2000; Wilcox et al. 2000). In contrast, transgenic potato plants downregulating MIPS activity via antisense RNA, not only presented a reduction of $7 \%$ in the inositol content but also showed smaller tubers, altered leaf morphology, precocious leaf senescence and reduced apical dominance (Keller et al. 1998).

The derived progenies were screened by PCR for the presence of both ahas gene (selective marker for tolerance to the herbicide imazapyr) and the $\triangle G m M I P S$ cassette. With the exception of line $12 \mathrm{i}$, the primary transformants $\left(\mathrm{T}_{0}\right)$ did not transfer the transgenes to their progenies ( $T_{1}$ generation). We observed that those lines, which did not transfer the transgenes to their progenies, presented a high frequency of seed abortion. The seeds stopped developing at 2-3 mm size (Fig. 1a).
This occurrence could be related to the role of phytate and myo-inositol, as reserve of phosphorus, precursor of molecules involved in signal transduction, stress protection, hormonal homeostasis and cell wall biosynthesis, which in turn are fundamental steps for the embryonic axis and cotyledon development (Stevenson et al. 2000).

To further investigate seed abortion and abnormal segregation, aborted and developing seeds were analyzed by PCR. An analysis of the 88 seeds generated from the 15 transgenic lines that did not transfer the transgenes to their progenies revealed that 69 had aborted. Sixty eight $(98.55 \%)$ aborted seeds presented both ahas and $\triangle G M M I P S$ cassettes while all developing seeds lacked the transgenes (Fig. 1b). Plants transformed only with the ahas cassette did not present abnormal seed abortion. These plants were also able to transfer the transgenes to their progenies. This result strongly suggests that the integration of the $\triangle G m M I P S$ cassette was responsible for abnormal seed abortion. Transgenic plants presented two fragments, one amplified from the $\triangle G m M I P S$ sequence and another from the endogenous genomic GmMIPS1 gene (Fig. 1b). Non-transgenic plants presented only the fragment amplified from the

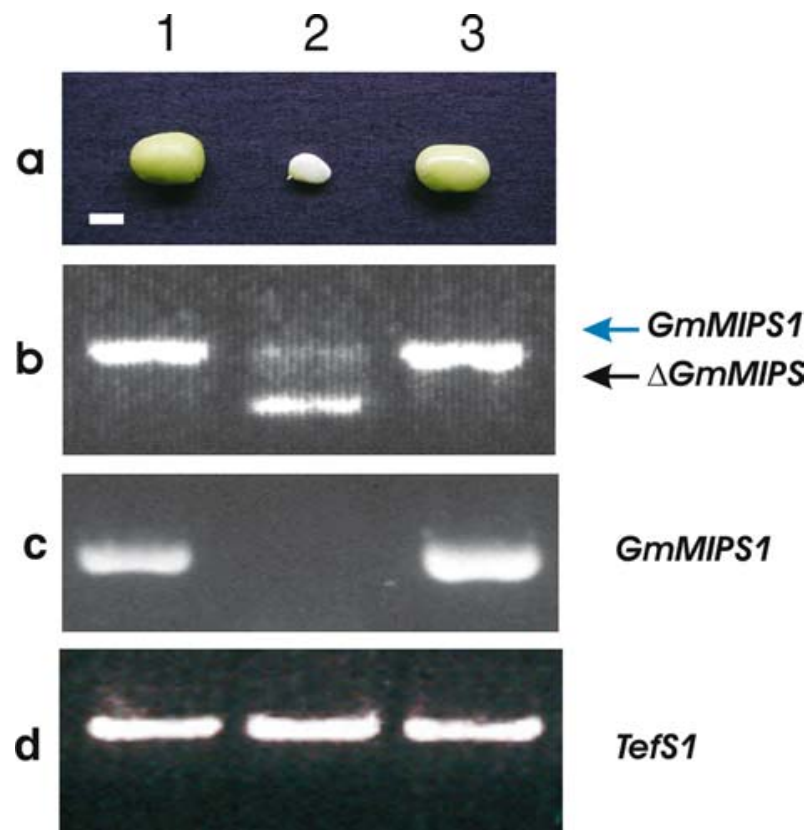

Fig. 1 Presence and expression of GmMIPS1 in soybean plants transformed with the $\triangle G m M I P S$ cassette. a Seeds derived from one pod presenting normal development (lanes 1 and 3) and nondeveloping (aborted) phenotypes (lane 2). Bar represents $2 \mathrm{~mm}$. b PCR analysis for the presence of the $\triangle G m M I P S$ cassette in developing seeds (lanes 1 and 3) and aborted seeds (lane 2). Blue arrow indicates the genomic GmMIPS1 gene. Black arrow shows the expected $706 \mathrm{bp}$ fragment amplified from the $\triangle G m M I P S$ sequence. The upper bands are consistent with the expected fragment amplified from the endogenous GmMIPS1 gene. c RTPCR analysis for the presence of transcripts from the endogenous GmMIPS1 gene in developing seeds (lanes 1 and 3) and aborted seeds (lane 2). d RT-PCR analysis for the presence of transcripts from the soybean tefS1 (elongation factor EF-1 $\alpha$, internal control) 


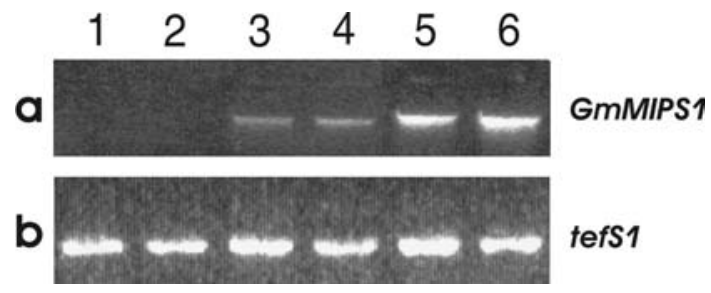

Fig. 2 Expression of the endogenous GmMIPS1 gene in transgenic soybean seeds ( $\mathrm{T}_{1}$ generation; $2-3 \mathrm{~mm}$ in size). a RT-PCR analysis for the presence GmMIPS1 from line 496i showing seed abortion (lanes 1 and 2 ) and from line $12 \mathrm{i}$ showing normal developed seeds (lanes 3 and 4). Lanes 5 and 6 represent non-transgenic seeds (controls). b RT-PCR analysis for the presence of transcripts from the soybean tefS1 (elongation factor EF-1 $\alpha$, internal control)

endogenous GmMIPS1 gene. In transgenic plants, the fragment from the GmMIPS1 gene was fainter compared to the fragment amplified from the $\triangle G m M I P S$. PCR conditions, template DNA, primers and nucleotide quantities may account for limited amplification of the endogenous larger fragment.

Normal and aborted seeds were analyzed by RT-PCR to detect endogenous GmMIPS1 transcripts. All developing seeds showed GmMIPS1 gene expression while the aborted seeds lacked GmMIPS1 gene expression (Fig. 1c). Both developing and aborted seeds presented the same level of the tefS1 (elongation factor EF-1 $\alpha$ ) housekeeping gene (Fig. 1d). The $706 \mathrm{bp}$ fragment corresponding to the MIPS-encoding sequence amplified from expressing seeds was sequenced. The sequence revealed high similarity when compared to the GmMIPSI $[100 \%(706 / 706)$ when compared to the GenBank accession AF293970 and 99.8\% (705/706) when compared to the TIGR Soybean Gene Index sequence TC215288]. In addition, the sequence revealed $89.9 \%$ identity $(635 / 706)$ to the sequence TC224821 published by the TIGR Soybean Gene Index (http://www.tigr.org). The results suggested that totally knocking out GMMIPS1 gene expression is lethal, which is probably due to the blocked inositol synthesis, but may also be due in part to the subsequent block in phytic acid synthesis. Our results are consistent with those of Hegeman et al. (2001) concerning GmMIPS1 gene expression in different soybean tissues and seed development stages. Steady state RNA levels were higher in developing seeds than in other soybean tissues, including flowers, leaves, roots, germinating cotyledons, and somatic embryos. GmMIPS1 transcripts were observed in $0-8 \mathrm{~mm}$ seeds, with maximum values being in 2-4 $\mathrm{mm}$ seeds. As development progressed, GmMIPS1 transcript levels decreased to nearly undetectable levels by 8-10 $\mathrm{mm}$ seeds (Hegeman et al. 2001).

Developing seeds $(2-3 \mathrm{~mm}$ in size) from line $12 \mathrm{i}$, which transfer the transgenes to the progeny $\left(T_{1}\right)$, were analyzed by RT-PCR to detect endogenous GmMIPSI transcripts. Results revealed a presence of GmMIPSI gene transcripts at a much lower level than observed in non-transgenic seeds (Fig. 2a). The line 496i that did not produce fertile transgenic seeds and presented seed abortion was chosen to be also analyzed by RT-PCR, and lacked GmMIPS1 gene expression (Fig. 2a). All seeds analyzed presented the same level of the tefSI (elongation factor EF-1 $\alpha$ ) housekeeping gene (Fig. 2b). Results demonstrated that line $12 \mathrm{i}$ is only partially knocking out GmMIPSI expression. This might explain the fact that line $12 \mathrm{i}$ is able to transfer the transgenes to the first generation, generating fertile developed seeds.

Using transmission electron microscopy, cells of aborted and normal seeds were studied for the presence of phytate, which appears as globular electron dense inclusions (phytin globoids or phytin bodies) associated with protein bodies (Jacobsen et al. 1971; Canini et al. 2001). Depending on the plant species, phytate globoids are located predominantly in the aleurone layer (wheat and barley) or in the embryo (maize; O'Dell et al. 1972). Our results have shown numerous phytin bodies in protodermal cells of developing seeds (Fig. 3a). However, no phytin bodies were observed in transgenic aborted seeds presenting silencing of the GMMIPS1 gene (Fig. 3b) thereby confirming the previous statement that conversion of glucose-6-phosphate to myo-inositol-1-
Fig. 3 Transmission electron micrographs of sections from the soybean cotyledonary protodermal cells. a Normal developing seed from a nontransgenic plant. b Aborted seed from a transgenic plant transformed with the $\triangle G m M I P S$ cassette. c Natural aborted seed from a nontransgenic plant. Ph phytin globoids (storage structures for phytate), $G$ Golgi apparatus, $N$ nucleus, $\mathrm{Cu}$ cuticle, black arrows mitochondria, white arrows endoplasmic reticulum. Bars represent $2 \mu \mathrm{m}$
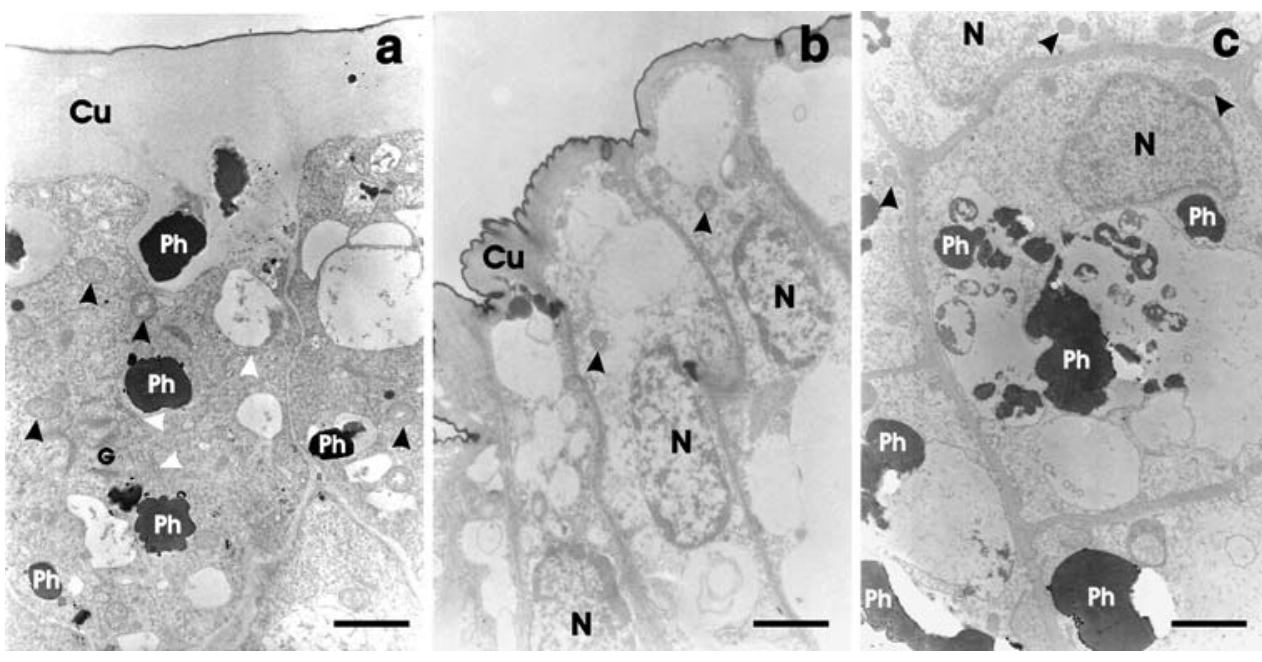


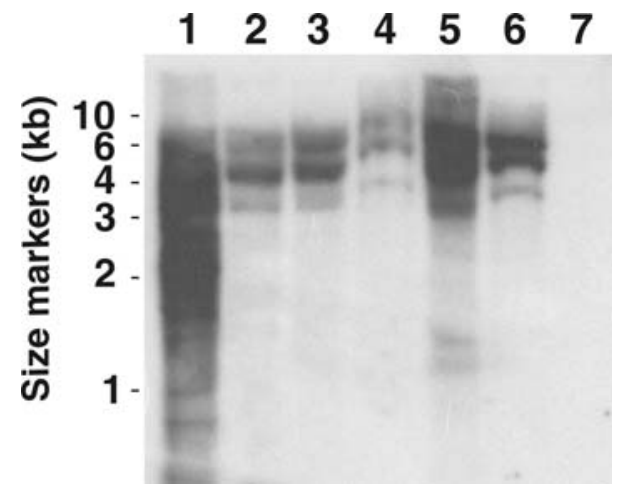

Fig. 4 Southern-blot analysis to detect the foreign $\triangle G m M I P S$ cassette in soybean plants $\left(\mathrm{T}_{2}\right.$ generation) from the line 12i. Lanes 1-6 transgenic plants; lane 7 non-transgenic plant

phosphate constrains phytic acid biosynthesis (Raboy and Dickinson 1987). Although phytin globoids might be important for seed development, we could not demonstrate that phytate is essential in this process. MIPS catalyzes myo-inositol synthesis, which plays a central role in several metabolic processes including signal transduction in the plant cell (York et al. 1999; Loewus and Murthy 2000; Odom et al. 2000; Stevenson et al. 2000; Brinch-Pedersen et al. 2002; Shen et al. 2003).

It is known that there are a small number of aborted seeds in normal soybean plants. Depending on the environmental conditions, this number could reach up to $29 \%$ (Tischner et al. 2003). In the present study, electron microscopy revealed phytin bodies in aborted seeds from non-transgenic soybean plants (Fig. 3c). These results demonstrate that natural abortion in these seeds was not correlated with phytate absence.

Induced mutagenesis has been one approach of reducing MIPS-encoding gene expression in plants. Hitz et al. (2002) reported a single recessive mutation in soybean, changing one amino acid residue (position 396, lysine to asparagine) in the mature peptide encoding the myo-inositol 1-phospate synthase gene, which decreases specific activity of the seed-expressed myo-inositol 1phosphate synthase by about $90 \%$. The mutated line presented decreased phytic acid level and retained seed viability. However, complete deletion of gene expression has not been achieved, probably due to the presence of several copies of the MIPS-encoding genes in the plant genome, reducing the probability of mutating and inactivating expression of all related genes at the same time. Indeed, the MIPS-encoding sequences represent gene families in some plant species. Seven sequences were found in maize (Larson and Raboy 1999), two in Arabidopsis (Johnson and Sussex 1995) and at least four in soybean (Hegeman et al. 2001). On the other hand, the strategy of interference RNA has been shown to be capable of generating post-transcriptional silence to quasi-undetectable levels of mRNA transcripts (Wesley et al. 2001; Scherer and Rossi 2003). Although Hegeman et al. (2001) showed data indicating that only the GmMIPS1 was expressed in immature cotyledons, we

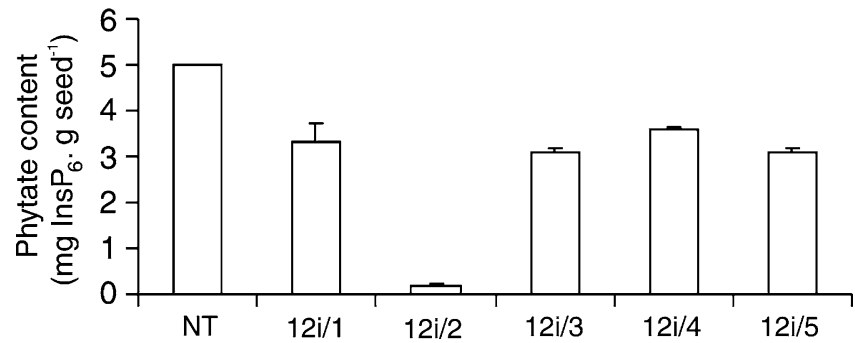

Fig. 5 Content of InsP $_{6}$ in mature seeds of transgenic sub-lines derived from line $12 \mathrm{i}(12 \mathrm{i} / 1,12 \mathrm{i} / 2,12 \mathrm{i} / 3,12 \mathrm{i} / 4,12 \mathrm{i} / 5)$ and nontransgenic line $(N T)$. InsP $\mathrm{P}_{6}$ was measured by HPLC in the $\mathrm{T}_{2}$ generation seeds. Error bars represent standard deviation from the mean $(n=3)$

can not definitively conclude that only the GmMIPSI gene was knocked out, because at least four MIPSencoding genes are present in the soybean genome and these genes have a high degree of sequence similarity.

Similar to other crops, soybean contains $60-80 \%$ of total seed phosphates in the form of phytate, which is a chelant agent; however, phytate is not readily digested by non-ruminant animals, reducing the nutritional value of soybean grains in feeding monogastric animals. Soybean meal is commonly supplemented with inorganic phosphorus, and more recently with the enzyme phytase to increase phosphorus bioavailability (Raboy et al. 2001; Raboy 2001, 2002). Moreover, phytate-derived phosphorus is excreted in the manure thereby contributing to environmental contamination (Raboy 2001, 2002; Shi et al. 2005). Consequently, there is a considerable biotechnological interest in reducing the phytate level in soybean seeds. This fact has induced us to evaluate soybean line $12 \mathrm{i}$, in which the RNA interfering $\triangle G m M I P S$ cassette is transmitted to the progeny.

Seeds from the first generation $\left(T_{1}\right)$ of line $12 \mathrm{i}$ germinated normally. After analysis by Southern blot, derived plants presented the foreign $\triangle G m M I P S$ cassette (Fig. 4). Line $12 \mathrm{i}$ was then separated into sub-lines (named 12i/1, $12 \mathrm{i} / 2,12 \mathrm{i} / 3,12 \mathrm{i} / 4$ and $12 \mathrm{i} / 5$ ) that were advanced to the $\mathrm{T}_{2}$ generation. Quantification of phytate $\left(\operatorname{InsP}_{6}\right)$ in mature

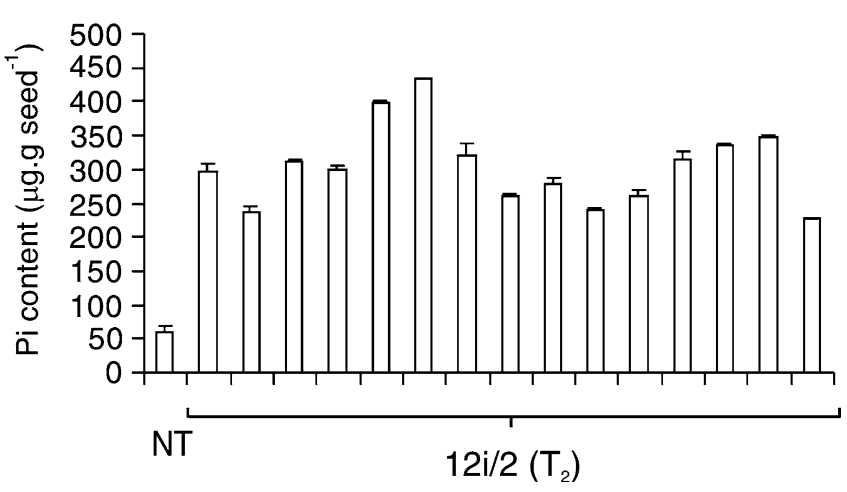

Fig. 6 Inorganic phosphorus $(P i)$ content in 15 transgenic mature seeds from the sub-line $12 \mathrm{i} / 2\left(\mathrm{~T}_{2}\right.$ generation). $N T$ non-transgenic seeds. Error bars represent standard deviation from the mean $(n=3)$ 
dry seeds of the sub-lines showed a reduction of 35-94.5\% (Fig. 5). Sub-line 12i/2 presented the highest reduction of phytate content reported so far, probably due to a partial silencing of the endogenous GmMIPS1. An indirect but simple screening procedure was utilized to detect putative low-phytate soybean grains. Seeds $\left(\mathrm{T}_{2}\right.$ generation) of the sub-line $12 \mathrm{i} / 2$ indicated an increase of 3.7 - to 6.7 -fold in inorganic phosphorus content (Fig. 6).

Recently, fertile transgenic soybean plants containing phytase were recovered, and a nearly threefold increase in phosphorus availability was found as well as a reduction of InsP6 levels from 12.6 to $24.8 \%$ (Chiera et al. 2004). The phytate reduction reported for soybean mutants generated by EMS treatment ranged from 28.9 to $55 \%$, with an increase in available phosphorus from threefold to sixfold (Wilcox et al. 2000). In contrast, our results showed the feasibility of reducing phytate in soybean seeds by as much as $94.5 \%$ (in sub-line $12 \mathrm{i} / 2$ ) without any negative effect on the plant phenotype.

Results of the present study demonstrated that silencing GmMIPS1 gene expression in soybean was an effective strategy to greatly reduce phytate content and improve phosphorus availability in soybean seeds. This technology is a foundation for production of low phytate varieties, resulting in improved nutrient availability for animal feed and reduced environmental impact of livestock production. Experiments have been carried out to evaluate utilization of the GmMIPS1 silencing strategy to inhibit seed development in fructiferous plants with the potential to develop seedless fruits.

Acknowledgements We thank Dr. Roger N. Beachy (Donald Danforth Plant Science Center) for his critical reading of the manuscript. A.C.S.N. was supported by a fellowship from CAPES.

\section{References}

Abu-Abied M, Holland D (1994) The gene c-inol from Citrus paradisi is highly homologous to turl and inol from yeast and Spirodela encoding for myo-inositol phosphate synthase. Plant Physiol 106:1689

Aragão FJL, Sarokin L, Vianna GR, Rech EL (2000) Selection of transgenic meristematic cells utilizing a herbicidal molecule results in the recovery of fertile transgenic soybean (Glycine max (L.) Merril) plants at high frequency. Theor Appl Genet 101:1-6

Brearley CA, Hanke DE (1996a) Metabolic evidence for the order of addition of individual phosphate esters to the myo-inositol moiety of inositol hexakisphosphate in the duckweed Spirodela polyrhiza L. Biochem J 314:227-233

Brearley CA, Hanke DE (1996b) Inositol phosphates in barley (Hordeum vulgare L.) aleurone tissue are stereochemical similar to the products of breakdown of $\mathrm{InsP}_{6}$ in vitro by wheat bran phytase. Biochem J 318:279-286

Brinch-Pedersen H, Sørensen LD, Holm PB (2002) Engineering crop plants: getting a handle on phosphate. Trends Plant Sci 7:118-125

Canini A, Leonardi D, Ruggeri S, Carnovale E, Caiola MG (2001) Intracellular localization of calcium, phosphorus and nitrogen in common bean seeds (Phaseolus vulgaris L. cv. Borlotto) by SEM, ESI and EELS techniques. Plant Biosyst 135:123-132

Chen PS, Toribara TY, Warner H (1956) Microdetermination of phosphorus. Anal Chem 28:1756-1758
Chiera JM, Finer JJ, Grabau EA (2004) Ectopic expression of a soybean phytase in developing seeds of Glycine max to improve phosphorus availability. Plant Mol Biol 56:895-904

Edwards K, Johnstone C, Thompson C (1991) A simple and rapid method for the preparation of plant genomic DNA for PCR analysis. Nucleic Acids Res 19:1349

Hara K, Yagi M, Koizumi N, Kusano T, Sano H (2000) Screening of wound-responsive genes identifies an immediateearly expressed gene encoding a highly charged protein in mechanically wounded tobacco plants. Plant Cell Physiol 41:684-691

Hatzack F, HuBel F, Zhang W, Hansen PE, Rasmussen SK (2001) Inositol phosphates from barley low-phytate grain mutants analysed by metal-dye detection HPLC and NMR. Biochem J 354:473-480

Hegeman CE, Good LL, Grabau EA (2001) Expression of D-myoInositol-3-phosphate synthase in soybean. Implications for phytic acid biosynthesis. Plant Physiol 125:1941-1948

Hitz WD, Carlson TJ, Kerr PS, Sebastian SA (2002) Biochemical and molecular characterization of a mutation that confers a decreased raffinosaccharide and phytic acid phenotype on soybean seeds. Plant Physiol 128:650-660

Ishitani M, Majumder AL, Bornhouser A, Michalowski CB, Jensen RG, Bohnert HJ (1996) Coordinate transcriptional induction of myo-inositol metabolism during environmental stress. Plant J 9:537-548

Jacobsen JV, Knox RB, Pyliotis NA (1971) The structure and composition of aleurone grains in the barley aleurone layer. Planta 101:189-209

Johnson MD (1994) The Arabidopsis thaliana myo-inositol 1phosphate synthase (EC5.5.1.4). Plant Physiol 105:1023-1024

Johnson MD, Sussex IM (1995) 1-L-myo-inositol 1-phosphate synthase from Arabidopsis thaliana. Plant Physiol 107:613-619

Keller R, Brearley CA, Trethewey RN, Müller-Röber B (1998) Reduced inositol content and altered morphology in transgenic potato plants inhibited for 1D-myo-inositol 3-phosphate synthase. Plant J 16:403-410

Larson SR, Raboy V (1999) Linkage mapping of maize and barley myo-inositol 1-phosphate synthase DNA sequences: correspondence with a low phytic acid mutation. Theor Appl Genet 99:27-36

Larson SR, Young KA, Cook A, Blake TK, Raboy V (1998) Linkage mapping of two mutations that reduce phytic acid content of barley grain. Theor Appl Genet 97:141-146

Larson SR, Rutger JN, Young KA, Raboy V (2000) Isolation and genetic mapping of a non-lethal rice (Oryza sativa L.) low phytic acid 1 mutation. Crop Sci 40:1397-1405

Loewus FA, Murthy PPN (2000) Myo-inositol metabolism in plants. Plant Sci 150:1-19

Ma F, Cholewa E, Mohamed T, Peterson CA, Gijzen M (2004) Cracks in the palisade cuticle of soybean seed coats correlate with their permeability to water. Ann Bot 94:213-228

Meinke DW, Chen J, Beachy RN (1981) Expression of storageprotein genes during soybean seed development. Planta 153:130-139

O'Dell BL, de Boland AR, Koirtyohann SR (1972) Distribution of phytate and nutritionally important elements among the morphological components of cereal grains. J Agric Food Chem 20:718-721

Odom AR, Stahlberg A, Wente SR, York JD (2000) A role for nuclear inositol 1,4,5-trisphosphate kinase in transcriptional control. Science 287:2026-2029

Raboy V (2001) Seeds for a better future: 'low phytate' grains help to overcome malnutrition and reduce pollution. Trends Plant Sci 6:458-462

Raboy V (2002) Progress in breeding low phytate crops. J Nutr 132:503S-505S

Raboy V, Dickinson DB (1987) The timing and rate of phytic acid accumulation in developing soybean seeds. Plant Physiol 85:841-844

Raboy V, Gerbasi PF, Young KA, Stoneberg SD, Pickett SG, Bauman AT, Murthy PPN, Sheridan WF, Ertl DS (2000) 
Origin and seed phenotype of maize low phytic acid 1-1 and low phytic acid 2.1. Plant Physiol 124:355-368

Raboy V, Young KA, Dorsch JA, Cook A (2001) Genetics and breeding of seed phosphorus and phytic acid. J Plant Physiol 158:489-497

Sambrook J, Russell DW (2001) Molecular cloning: a laboratory manual, 3rd edn. Cold Spring Harbor Laboratory Press, Cold Spring Harbor

Sandberg A-S, Ahderinne R (1986) HPLC method for determination of inositol tri, tetra-, penta-, and hexaphosphates in foods and intestinal contents. J Food Sci 51:547-550

Scherer LJ, Rossi JJ (2003) Approaches for the sequence-specific knockdown of mRNA. Nat Biotechnol 21:1457-1465

Shen X, Xiao H, Ranallo R, Wu WH, Wu C (2003) Modulation of ATP-dependent chromatin-remodeling complexes by inositol polyphosphates. Science 299:112-114

Shi J, Wang H, Hazebroek J, Ertl DE, Harp T (2005) The maize lowphytic acid 3 encodes a myo-inositol kinase that plays a role in phytic acid biosynthesis in developing seeds. Plant J 42:708-719

Smart CC, Fleming AJ (1993) A plant gene with homology to D$m y o$-inositol-3-phosphate synthase is rapidly and spatially upregulated during an abscisic-acid-induced morphogenic response in Spirodela polyrrhiza. Plant J 4:279-293
Stevenson JM, Perera IY, Heilmann I, Persson S, Boss WF (2000) Inositol signaling and plant growth. Trends Plant Sci 5:252-258

Tischner T, Allphin L, Chase K, Orf JH, Lark KG (2003) Genetics of seed abortion and reproductive traits in soybean. Crop Sci 43:464-473

Wesley SV, Helliwell CA, Smith NA, Wang MB, Rouse DT, Liu Q, Gooding PS, Singh SP, Abbott D, Stoutjesdijk PA, Robinson SP, Gleave AP, Green AG, Waterhouse PM (2001) Construct design for efficient, effective and high throughput gene silencing in plants. Plant $\mathbf{J}$ 27:581-590

Wilcox J, Premachandra G, Yound K, Raboy V (2000) Isolation of high seed inorganic P, low-phytate soybean mutants. Crop Sci 40:1601-1605

York JD, Odom AR, Murphy R, Ives EB, Wente SR (1999) A phospholipase C-dependent inositol polyphosphate kinase pathway required for efficient messenger RNA export. Science 285:96-100 